\title{
RELACIÓN ENTRE EL ESTADO SEROLÓGICO A LEUCOSIS BOVINA ENZOÓTICA Y PARÁMETROS REPRODUCTIVOS EN HATOS LECHEROS ESPECIALIZADOS DE COSTA RICA
}

\author{
Juan José Romero ${ }^{l / *}$, Gerardo Dávila**, Gabriela Beita***, Gaby Dolz ${ }^{* * *}$ \\ Palabras clave: Virus; reproducción; lechería; sistema de información; trópico. \\ Keywords: Virus; reproduction; dairy; information system; tropics.
}

Recibido: 21/10/14

Aceptado: 04/03/15

\begin{abstract}
RESUMEN
Se realizó un estudio longitudinal y analítico para determinar la relación entre el estado serológico al virus de la leucosis bovina enzoótica (VLBE) y los parámetros reproductivos, en 26 fincas lecheras de Costa Rica usuarias del programa VAMPP Bovino. Se realizó un primer muestreo en 2006-2007 en animales mayores de 6 meses de edad; luego, en 2009, se realizó el segundo muestreo en las vacas seronegativas del 2006-2007. Se calculó la incidencia acumulada (IA) global y por finca y, mediante Chi-cuadrado, se realizó la comparación de IA, según raza y número de lactancia. La relación entre el estado serológico al VLBV y el intervalo entre partos (IEP), servicios por concepción (SPC) y días abiertos (DA) por grupos de lactancia y raza, se determinó con la prueba de Kruskal-Wallis. La incidencia global fue de 21,8\% (173/794), con $38,5 \%$ de las fincas con incidencias mayores al $40 \%$. La tasa de seroconversión en vacas con 1-2 lactancias $(23,5 \%)$ fue diferente a la de $\geq 6$ lactancias $(\mathrm{p}=0,03)$. Las medias raza Holstein $\mathrm{x}$ Jersey (H4J4) presentaron la mayor incidencia (33,3\%), seguidas por las Holstein (27,1\%). Según los finqueros, en las 26 fincas (100\%) se utilizaba
\end{abstract}

Autor para correspondencia. Correo electrónico: juan.romero.zuniga@una.cr

Programa de Investigación en Medicina Poblacional. Escuela de Medicina Veterinaria, Universidad Nacional, Costa Rica. PO Box: 304-3000 Heredia.

\begin{abstract}
Relationship between the serological status towards enzootic bovine leukosis and reproductive parameters in specialized dairy herds in Costa Rica. An analytical longitudinal study was conducted to determine the cumulative incidence, and the relationship of the serostatus towards enzootic bovine leukosis virus (EBLV) and reproductive parameters, in 26 dairy farms in Costa Rica using the VAMPP Bovine information system. A first sampling was carried out in 20062007 in animals older than 6 months old; then, in 2009 , a second sampling was performed in all cows seronegative in 2006-2007. The overall and farmspecific cumulative incidence were calculated; then, comparisons of these were performed by race and parity number, using the Chi-square test. The relationship of EBLV status with the calving interval (CI), services per conception (SPC) and days open (DO) by parity number and race groups, was determined using the Kruskal-Wallis test. The overall incidence was $21.8 \%$ (173/794), with $38.5 \%$ of farms with incidences higher to $40 \%$. The seroconversion rate in cows with $1-2$ parities (23.5\%) was different than those with 6 or more parities $(\mathrm{p}=0.03)$. Holstein $\mathrm{x}$ Jersey cows \footnotetext{
Nicaragua.

*** Laboratorio de Entomología, Programa de Investigación en Medicina Poblacional. Escuela de Medicina Veterinaria, Universidad Nacional, Costa Rica. PO Box: 86-3000 Heredia.
}

** Universidad de Agricultura y Ganadería. Rivas,
\end{abstract}


una aguja y un guante de palpación por animal; sin embargo, el 53,8\% mostraron incidencias superiores al 15\%. En general, hubo tendencia a menores IEP en seronegativas con respecto a seropositivas y seroconvertidas, especialmente en seropositivas de $1-2$ lactancias $(\mathrm{p}=0,017)$ y de $3-5$ lactancias $(p=0,038)$. Sin clasificar por número de lactancia o raza, las seropositivas y seroconvertidas necesitan más $\mathrm{SPC}(\mathrm{p}=0,03)$; esta misma tendencia (no significativa), se observó en DA. Así, se pudo comprobar alguna relación entre el estado a VLBE y el IEP y SPC, no así con DA, aunque no hubo significancia estadística en algunas de las diferencias encontradas, al ser mejores los parámetros en las seronegativas.

\section{INTRODUCCIÓN}

La Leucosis Bovina Enzoótica (LBE) es causada por el virus de la leucosis bovina enzoótica (VLB), perteneciente a la familia Retroviridae del género Deltaretrovirus (Murphy et ál. 1999). Asimismo, la leucosis bovina es un trastorno patológico que se caracteriza por una proliferación o crecimiento descontrolado del tejido formador de leucocitos (Radostits et ál. 2001).

En Costa Rica, la LBE fue diagnosticada y reportada por primera vez en la Escuela de Medicina Veterinaria en el año de 1976 (González 1977). Desde entonces, la seroprevalencia del VLBE reportada en Costa Rica durante 20 años no ha variado mucho; un estudio realizado por Beita 2008 determinó una seroprevalencia de $41 \%$ a nivel de animales y del $97,4 \%$ a nivel de hatos lecheros especializados (Rodríguez et ál. 1980, Jiménez et ál. 1995, Dolz y Moreno 1999, Beita 2008).

Una de las principales dificultades de implementar programas de control y erradicación had the highest incidence (33.3\%), followed by Holstein (27.1\%). According to the farmers, in the 26 farms (100\%) they used an individual needle and a single rectal palpation glove per animal; however, $53.8 \%$ of farms showed incidences above $15 \%$. In general, there was a tendency to lower CI in seronegative cows with regard to seropositives and seroconverters, especially in seropoisitives of 1-2 lactations $(\mathrm{p}=0.017)$ and 3-5 lactations $(\mathrm{p}=0.038)$. Regardless parity number or race, the seropositives and seroconverters required more $\mathrm{SPC}(\mathrm{p}=0.031)$; this same tendency (not significant) was observed in DO. Thus, it was found some relation of the status about EBLV with CI and SPC, but not with DO, although there was no statistical significance in some of the differences found, with better parameters in seronegative cows.

de la enfermedad radica en que la LBE cursa con enfermedad clínica (linfosarcoma) únicamente en un $10 \%$ de las vacas infectadas después de un período de incubación de 2 a 8 años, mientras que un $30 \%$ de los animales infectados desarrollarán linfocitosis persistente (LP) sin signos clínicos aparentes, aunque un 100\% de los animales infectados desarrollarán anticuerpos contra el virus y permanecerán infectados con el virus de por vida, que represente una fuente de infección para otras vacas (Kettmann et ál. 1980, Brenner et ál. 1989).

Estudios sobre el efecto que ocasiona el VLBE sobre la producción y reproducción de animales seropositivos han sido inconsistentes y contradictorios, y se centran en las pérdidas económicas que se registran, sobre todo, a un aumento en los costos de reemplazo de animales seropositivos y en las pérdidas ocasionadas por las restricciones en la exportación de ganado bovino seropositivo. Sin embargo, algunos investigadores han encontrado una disminución en algunos parámetros reproductivos de los animales infectados 
con el VLBE (Brenner et ál. 1989, Pollari et ál. 1992, Mora 1997, D’Angelino et ál. 1998); mientras que otros no han determinado relación alguno (Huber et ál. 1981).

Estudios realizados para determinar el efecto del VLBE sobre el intervalo entre partos (IEP) determinaron diferencias de 19 días más del IEP en vacas seropositivas comparadas con seronegativas, sin embargo, la diferencia no fue significativa (D’Angelino et ál. 1998). En otro estudio, Pollari et ál. (1992) compararon los IEP de vacas seronegativas con los de vacas seropositivas con y sin linfocitosis y otro grupo con linfosarcoma, al determinarse valores de 12,$05 ; 12,50 ; 12,87$ y 12,97 meses, respectivamente; aunque no determinaron significancia, reportaron una tendencia a mayor IEP entre los grupos con la infección y, especialmente, con la enfermedad clínica. En contraste, Huber et ál. (1981) no determinaron diferencia alguna entre IEP entre vacas seropositivas y seronegativas.

Con respecto a los días abiertos, Brenner et ál. (1989) determinaron 48 días abiertos más en animales seropositivos al compararlos con vacas seronegativas, mientras que Pollari et ál. (1992) encontraron una diferencia de 12,19 y 22 más en vacas seropositivas con y sin linfocitosis y vacas con linfosarcoma respecto a las seronegativas. En contraposición, Huber et ál. (1981) no determinaron diferencia en los días abiertos entre vacas seropositivas y seronegativas. En Costa Rica, Mora (1997) determinó que vacas seronegativas tenían menos días abiertos; sin embargo, la muestra analizada no fue lo suficientemente grande, para sustentar estadísticamente el resultado, lo que representa solamente una tendencia.

Debido a la controversia en los resultados obtenidos en los diferentes estudios realizados respecto a la relación que tiene la infección al VLBE con los parámetros reproductivos, se realizó este estudio longitudinal en hatos lecheros especializados para determinar si, en efecto, el VLBE afecta negativamente los principales parámetros reproductivos.

\section{MATERIALES Y MÉTODOS}

\section{Tipo de estudio, población y tamaño de la muestra}

Se realizó un estudio longitudinal y analítico (Argimon y Jiménez 1991) en un total de 26 fincas de lechería especializada; 4 en San José, 4 en Heredia, 8 en Cartago y 10 en Alajuela. Se consideran especializadas en la producción de leche por tener alta genética de razas productoras de leche, registrar promedios de producción altos, realizar 2 ordeños diarios, contar con equipo de ordeño automático en distintos tipos de salas, utilizar suplementos nutricionales, tener potreros con pastos mejorados y una serie de instalaciones adicionales como maternidad, cunas para reemplazos, sala de tanque enfriador, entre otras. Adicionalmente, cuentan con asesoramiento de médico veterinario al menos una vez al mes. Todas poseían registros automatizados mediante el programa VAMPP Bovino (Noordhuizen y Buurman 1984, Romero et ál. 2011) actualizado al 2009. Un primer muestreo se realizó en 2006-2007 (Beita 2008) al muestrear a todos los animales mayores de 6 meses de edad. Luego, en 2009 se realizó el segundo muestreo, en que se tomaron muestras de sangre de todas las vacas que habían resultado seronegativas en el 20062007. Las vacas que fueron seropositivas en el primer muestreo y que estaban aún presentes en las fincas durante el segundo muestreo, no fueron sangradas en este muestreo ya que el VLBE ocasiona infecciones persistentes, y se asumió que el estado de seropositividad se había mantenido desde el primer muestreo.

Para realizar las comparaciones de parámetros productivos entre las diferentes categorías de vacas (seropositivas, seronegativas y seroconvertidas), el tamaño de muestra por grupo se calculó por medio de la fórmula para diferencia de promedios (Daniel 2002) para 2 parámetros primarios: intervalo entre partos (IEP) y días abiertos (DA). En el caso del IEP se asumió una diferencia de medias de 30 días (390 vs. 420) con una desviación estándar esperada de 80 días 
(Alvarado et ál. 2007), mientras que para los DA se asumió una diferencia de 20 días (110 vs. 130) con una desviación estándar esperada de 60 días, con un nivel de confianza del $95 \%$ y una potencia del 80\%. Esto arrojó una muestra mínima de 117 vacas por grupo para el IEP y 144 para los DA.

No obstante, en el presente estudio se analizaron los datos para un total de 527 animales seropositivos en el período, 621 que fueron siempre seronegativas y 173 que seroconvirtieron entre el primer y segundo muestreo. No todas estas vacas tuvieron datos para los 3 indicadores medidos. A la vacas seropositivas al primer muestreo, y aun presentes en el segundo muestreo, no se les tomó muestra de sangre para su procesamiento, pues se asumió que el estado de seropositividad no había cambiado en esos 2 años (infección persistente).

Los animales se agruparon en 3 categorías de lactancias: el primer grupo con 1 y 2 lactancias, el segundo con 3 a 5 lactancias y un último grupo con vacas con $\geq 6$ lactancias. Los bovinos analizados fueron de las razas Holstein (> 6/8 Holstein), Jersey ( $>$ 6/8 Jersey), H4J4 (4/8 Holstein $+4 / 8$ Jersey; $5 / 8$ Jersey $+3 / 8$ Holstein, $3 / 8$ Jersey $+5 / 8$ Holstein) (Romero et ál. 2012), Guernsey ( $>6 / 8$ Guernsey) y un último grupo donde se aglomeraron todas las vacas de otras razas, a este grupo se denominó como "Otras".

Para los animales seleccionados se extrajo, de la Base Nacional de Datos del programa VAMPP Bovino (Romero et ál. 2011), los siguientes parámetros reproductivos: intervalos entre partos (IEP), servicios por concepción (SPC) y días abiertos (DA) del período 2008-2009.

\section{Toma de muestra y aplicación de la encuesta}

Se tomó una muestra de sangre a las vacas seleccionadas mediante punción de la vena coccígea media, con el uso de Vacutainer®. Las muestras se trasladaron al laboratorio en hieleras a temperatura cercana a $4-7^{\circ} \mathrm{C}$. En el laboratorio se separó el suero y se realizó la prueba serológica con el ELISA indirecto para determinar seropositividad o seronegatividad al VLBE. Se reporta un
$100 \%$ de sensibilidad y un $99,7 \%$ de especificidad para esta prueba (Svanova 2015).

Con el objetivo de tener un panorama referente al manejo zoosanitario de la finca con respecto a medidas específicas que se realizan para evitar la transmisión del VLBE de forma iatrogénica mediante la inoculación de sangre de un animal a otro, se aplicó una encuesta a cada uno de los dueños o a la persona responsable de la finca y que tuviera pleno dominio de las actividades en la lechería. La encuesta incluyó únicamente preguntas cerradas. Este instrumento fue previamente validado mediante la aplicación a 5 productores tomados a azar dentro del grupo de usuarios de VAMPP Bovino. Los resultados de la encuesta se analizaron mediante el cálculo de las frecuencias relativas (porcentajes). Dado el pequeño tamaño de la muestra, no se realizaron pruebas de hipótesis para comparación de porcentajes.

\section{Definición de las variables}

Seronegatividad: Variable categórica dicotómica. Condición inmunológica caracterizada por la ausencia de anticuerpos específicos en la sangre, en este caso contra el VLBE. Una vaca se consideró negativa en este estudio cuando el suero analizado en la prueba de ELISA arrojó $\mathrm{PP}<20 \%$ durante las 2 lactancias incluidas en el estudio.

Seropositividad: Variable categórica dicotómica. Se refiere a la condición inmunológica caracterizada por la presencia de anticuerpos específicos en la sangre, en este caso contra el VLBE. Una vaca se consideró positiva en este estudio cuando el suero analizado arrojó un $\mathrm{PP} \geq 20 \%$ durante las 2 lactancias incluidas en el estudio.

Seroconversión: Variable categoría dicotómica. Condición inmunológica caracterizada por la aparición de anticuerpos en una muestra, posterior a una condición de seronegatividad. Se consideró seroconversión en un animal cuando el suero analizado en el primer muestreo arrojó un $\mathrm{PP}<$ de $20 \%$ y en el segundo muestreo un $\mathrm{PP} \geq$ a $20 \%$. 
Intervalo entre partos (IEP): Variable numérica continua medida en días del tiempo transcurrido entre un parto y el siguiente.

Servicios por concepción (SPC): Variable numérica discreta que contabiliza el número de montas que necesitó una vaca para quedar gestada.

Días abiertos (DA): Variable numérica continúa medida en días para el tiempo transcurrido entre el parto y una nueva concepción.

Área de cuarentena: Variable dicotómica (Sí/No). ¿Existe un área en la finca destinada exclusivamente para mantener animales enfermos o sospechosos de sufrir enfermedades infecciosas, con el objetivo de evitar el contacto entre animales sanos y enfermos y tratar de controlar la transmisión de enfermedades infectocontagiosas intra hato?

Aguja por animal: Variable dicotómica (Sí/No). ¿Se utiliza una aguja descartable por animal cuando se realizan en la finca actividades como vacunaciones, desparasitaciones, vitaminaciones o alguna otra actividad que requiere el uso de agujas?

Guante por animal: Variable dicotómica (Sí/No). ¿Se utiliza un guante por vaca cuando se realizaron labores como diagnóstico reproductivo por palpación rectal, inseminación artificial, tratamiento intrauterino u otra labor que requirió uso de guante?

Examen de Leucosis Bovina Enzoótica: Variable dicotómica (Sí/No). ¿Realizan los productores un examen para detectar el VLBE a los animales que ingresan a su finca?

Desinfección de equipo: Variable dicotómica (Sí/No). ¿Se desinfecta la tatuadora o el equipo que se utiliza para descornar entre animales en la finca?

Separación de los animales: Variable dicotómica (Sí/No). ¿Se segregan en 2 grupos aparte los animales del hato según su estado de seropositivos y seronegativos al VLBE?

Toro negativo: Variable dicotómica (Sí/ No). ¿Se utilizan únicamente toros seronegativos al VLBV para la reproducción en el hato?
Semen negativo: Variable dicotómica (Sí/ No). ¿Se usa, exclusivamente, semen negativo al VLBE para la inseminación de las vacas del hato?

Pasteurización del calostro: Variable dicotómica $(\mathrm{S} i ́ / \mathrm{No})$. ¿Se realiza el un proceso térmico $\left(65^{\circ} \mathrm{C}\right.$ por 15 minutos o bien, $105^{\circ} \mathrm{C}$ por 15 segundos) al calostro antes de ofrecérselo a los terneros?

\section{Análisis serológico}

La prueba de ELISA se realizó por medio del protocolo recomendado por la compañía SVANOVA®. Así, se añadió $100 \mu \mathrm{l}$ de tampón de dilución a cada pozo cubierto con antígeno VLBE; seguidamente, se agregó $4 \mu \mathrm{l}$ de suero de la muestra a analizar y suero control positivo (por duplicado) y control negativo (por duplicado), se agitó la placa y se incubó 1 hora a $37^{\circ} \mathrm{C}$. Posteriormente, se lavó 3 veces con tampón de lavado, se le añadieron $100 \mu 1$ de conjugado (anti IgG bovinaperoxidasa) a cada pozo y se volvió a incubar por 1 hora a $37^{\circ} \mathrm{C}$; se lavó de nuevo 3 veces y se agregó sustrato (tetrametilbenzidine) a cada pozo. Se incubó una última vez a temperatura ambiente por 10 minutos. Finalmente, la reacción se paró con $50 \mu \mathrm{l}$ de solución de parado (ácido sulfúrico) y se determinó la densidad óptica (DO) a $450 \mathrm{~nm}$. Se consideró válido el ensayo si el control positivo mostró una DO mayor a 1,0 y el suero control negativo arrojó un porcentaje de positividad (PP) menor o igual a $15 \%$. El porcentaje de positividad (PP) se calculó con la siguiente fórmula:

$$
\mathrm{PP}=\frac{\text { DO de la muestra o del control negativo }}{\text { DO de control positivo }} \times 100
$$

Según indicaciones del fabricante, los sueros analizados que arrojaron un PP mayor o igual a $20 \%$ se consideraron positivos al VLBE.

\section{Análisis Estadístico}

Vacas seronegativas en el primer muestreo y seropositivas al VLBE en el segundo se consideraron casos nuevos (incidentes). La incidencia acumulada (IA) global y por finca se determinó según la fórmula: 
Se realizó, además, una comparación de porcentajes (incidencias acumulativas) según raza y número de lactancia mediante la prueba de Chicuadrado (Daniel 2002).

El análisis de la asociación del estado serológico con los parámetros reproductivos por grupos de lactancia y por raza, de manera aislada, se realizó con la prueba de Kruskal-Wallis. Para efectos de este análisis, los parámetros de los animales que no cambiaron su estado (seropositivos y seronegativos) fueron tomados los datos reproductivos de las lactancias completas en el período de estudio, incluyendo los indicadores presentes hasta el momento del segundo muestreo. En el caso de las vacas que seroconvirtieron se tomó en cuenta únicamente los datos de la última lactancia, que es de la que tiene certeza de su condición serológica. Es por esto que el número de registros incluidos en el análisis de la relación del estado serológico con los parámetros reproductivos sobrepasa el total de animales incluidos en el estudio.

Todos los cálculos se realizaron con el programa estadístico Infostat ${ }^{\circledR}$ (Di Rienzo et ál. 2008). Valores de $\mathrm{p}<0,05$ se consideraron estadísticamente significativos.

\section{RESULTADOS Y DISCUSIÓN}

\section{Incidencia}

Del total de 794 vacas lecheras de las 26 fincas analizadas en el presente estudio con resultado negativo al inicio del período, 173 seroconvirtieron y las restantes 640 se determinaron seronegativas, que da como resultado una incidencia global de $21,8 \%$. Un total de $10(38,5 \%)$ fincas mostró una incidencia mayor al 40\%, 4 $(15,4 \%)$ entre 15 y $40 \%$ y $12(50,0 \%)$ una incidencia menor a $15,0 \%$ (Cuadro 1).

Cuadro 1. Incidencia acumulada del VLBE determinada en 26 fincas lecheras especializadas, Costa Rica, 2007-2009.

\begin{tabular}{cccc}
\hline Finca & Animales positivos / Total & Incidencia acumulada & Prevalencia reportada en 2008 \\
\hline 1 & $4 / 8$ & 50,0 & 64,1 \\
2 & $5 / 26$ & 19,2 & 48,6 \\
3 & $1 / 28$ & 3,6 & 24,1 \\
4 & $26 / 34$ & 76,5 & 63,2 \\
5 & $2 / 27$ & 7,4 & 36,1 \\
6 & $9 / 12$ & 75,0 & 57,0 \\
7 & $19 / 33$ & 57,6 & 65,5 \\
8 & $11 / 11$ & 100,0 & 69,6 \\
9 & $1 / 65$ & 1,5 & 4,9 \\
10 & $14 / 28$ & 50,0 & 52,3 \\
11 & $10 / 14$ & 71,4 & 60,1 \\
12 & $2 / 18$ & 11,1 & 46,7 \\
13 & $0 / 51$ & 0,0 & 1,3 \\
14 & $0 / 63$ & 0,0 & 5,4 \\
15 & $15 / 23$ & 65,2 & 55,4 \\
16 & $0 / 26$ & 0,0 & 10,4 \\
17 & $0 / 32$ & 0,0 & 4,2 \\
18 & $3 / 41$ & 7,3 & 26,2 \\
19 & $5 / 22$ & 22,7 & 75,6 \\
20 & $8 / 25$ & 32,0 & 46,7 \\
21 & $10 / 79$ & 12,7 & 35,6 \\
22 & $5 / 12$ & 41,7 & 73,5 \\
23 & $5 / 19$ & 26,3 & 12,3 \\
24 & $1 / 40$ & 2,5 & 2,7 \\
25 & $3 / 39$ & 7,7 & 28,1 \\
26 & $14 / 18$ & 77,8 & 73,5 \\
\hline Total & $173 / 794$ & 21,8 & \\
\hline
\end{tabular}


Al analizar la incidencia con respecto al grupo de lactancia se determinó una mayor tasa de seroconversión en el grupo de animales con 1-2 lactancias $(23,5 \%)$, con una diferencia significativa $(\mathrm{p}=0,03)$ únicamente respecto a las de 6 o más lactancias (Cuadro 2).

Cuadro 2. Incidencia del VLBE en bovinos, según raza y número de lactancias, en 26 fincas lecheras especializadas, Costa Rica, 2007-2009.

\begin{tabular}{llcccc}
\hline Variable & \multicolumn{1}{c}{ Estrato } & Total Animales & Negativos & Seroconvertidos & Incidencia (\%) \\
\hline Raza & Holstein & 310 & 226 & 84 & $27,1^{\mathrm{a}}$ \\
& Jersey & 369 & 311 & 58 & $15,7^{\mathrm{b}}$ \\
& Holstein x Jersey & 24 & 16 & 8 & $33,3^{\mathrm{a}}$ \\
& Guernsey & 29 & 28 & 3 & $10,3^{\mathrm{b}}$ \\
& Otras & 62 & 40 & 20 & $32,3^{\mathrm{a}}$ \\
\hline Lactancia & $1-2$ & 612 & 451 & 144 & $23,5^{\mathrm{a}}$ \\
& $3-5$ & 153 & 143 & 27 & $17,7^{\mathrm{b}}$ \\
& $\geq 6$ & 29 & 27 & 2 & $6,9^{\mathrm{bc}}$ \\
\hline Total & & 794 & 621 & 173 & 21,8 \\
\hline
\end{tabular}

Literales distintas indican diferencias significativas con nivel de significancia de 0,05 .

Al comparar la incidencia del VLBE en vacas según número de lactancias, se determinó que vacas en la primera lactancia mostraron los más altos porcentajes $(23,5 \%)$, lo que coincide con lo reportado por Beita (2008) y Johnson y Kaneene (1991), de que la prevalencia del VLBE aumenta en forma significativa en el ganado en el momento en que los bovinos ingresan al hato en producción, ya que son sometidos a un manejo más intensivo, lo cual conlleva a un riesgo de infección, ya sea por aumento de la intervención humana (transmisión iatrogénica) o por contacto directo y prolongado con animales infectados (transmisión horizontal).

La incidencia con respecto a la raza de los animales fue mayor en los animales de cruce Holstein x Jersey (33,3\%), seguido de la raza Holstein (27,1\%). En los animales Guernsey y Jersey se determinó baja incidencia (Cuadro 2). $\mathrm{La}$ alta incidencia determinada en vacas de la raza Holstein (26,5\%), en comparación con la incidencia en vacas Jersey $(11,9 \%)$, confirma lo reportado previamente por Beita (2008), lo que se explica con la alta susceptibilidad de vacas Holstein infectadas con el VLBE a desarrollar linfocitosis persistente y tumores linfoides (Detilleux et ál. 1991) y por consiguiente la transmisión más eficaz de estos linfocitos (Kettmann et ál. 1980).

\section{Condiciones de manejo relacionadas con la infección por el VLBE}

Según la información autorreferida por los finqueros respecto a las medidas de manejo zoosanitarias realizadas en las fincas participantes, en las 26 fincas analizadas se realizaban las medidas más importantes para evitar la transmisión del VLBE, que es la utilización de una aguja y un guante por animal (100\%). Desde hace varias décadas se ha descrito que si bien las rutas de transmisión vertical por medio del consumo de calostro o leche contaminada, o in-útero, juegan un rol en el total de nuevas infecciones por VLBE, la mayor incidencia se produce por transmisión iatrogénica a través del contagio por uso de transferencia de sangre entre vacas, especialmente en el uso de equipo, utensilios o guantes de palpación rectal (Hopkins y DiGiacomo 1997, Nekouei et ál. 2015).

El detalle de los resultados de la encuesta realizada a los productores se muestra en el Cuadro 3. Sin embargo, a pesar de los resultados, 
Cuadro 3. Frecuencia absoluta y relativa de respuestas positivas a las encuestas realizada sobre las prácticas de manejo en 26 fincas lecheras de Costa Rica, 2007-2009.

\begin{tabular}{lcc}
\hline Tópicos & Sí & $(\%)$ \\
\hline Existe un área de cuarentena para los animales enfermos & 12 & 46 \\
Utilizan una aguja por animal & 26 & 100 \\
Utilizan un guante por animal & 26 & 100 \\
Realizan examen para detectar el VLBE a las hembras de reemplazo & 14 & 54 \\
Introducen solamente animales negativos al VLBE & 26 & 100 \\
Desinfectan la tatuadora entre un animal y otro & 25 & 96 \\
Desinfectan cuchillos y navajas utilizados entre un animal y otro & 25 & 96 \\
Realizan descarte o separación de animales seropositivos VLBE & 13 & 50 \\
Utilizan toros negativos al VLBE destinados a monta natural en la finca & 24 & 92 \\
Utilizan semen de toros provenientes de Europa & 6 & 23 \\
Calientan el calostro y la leche que se les suministra a las terneras & 12 & 46 \\
\hline
\end{tabular}

la incidencia acumulativa en muchas fincas, en un período de 2 o 3 lactancias, alcanzó el 21,8\%, pero con máximos de $100 \%$, y las prevalencias no bajaron sustancialmente (Cuadro 1). Asimismo, $14 / 26$ fincas $(53,8 \%)$ mostraron incidencias superiores al $15 \%$, lo cual es muy alto y poco probable si, en efecto, el $100 \%$ de las fincas hubieran realizado las prácticas de usar un solo guante y una sola aguja desechable por animal (Cuadro 3). Esto es, posiblemente, debido a un fenómeno de sesgo de información diferencial (Greenberg et ál. 2001), pues en diversas capacitaciones, cursos, congresos e, incluso por la retroalimentación dada por Beita (2008) a los encargados de las fincas como parte de su investigación en 20062007, los informantes conocen de lo que técnicamente se debe hacer pero que no necesariamente realizan. Debido a esta situación, se prescindió del análisis de factores de riesgo según prácticas realizadas en las fincas, ya que las respuestas de la encuesta no se consideraron confiables.

\section{Relación entre el estado serológico con los parámetros reproductivos}

En general, se mostró una tendencia a menores IEP en seronegativas, con ausencia de diferencia significativa entre seropositivas y seroconvertidas. Cuando se analiza la relación del estado serológico al VLBE con el IEP según el número de lactancia, se determinó un efecto significativo en el grupo de vacas de 1-2 lactancias $(\mathrm{p}=0,017)$, con diferencias de 21 días entre vacas seronegativas y seropositivas. En el grupo de vacas de 3-5 lactancias $(\mathrm{p}=0,038)$, las vacas seronegativas mostraron IEP más cortos (Cuadro 4). Este resultado concuerda con lo reportado por D’Angelino et ál. (1998), los cuales reportan una diferencia de +19 días en las seropositivas, y con Pollari et ál. (1992), quienes determinaron 13, 23 y 26 días de IEP en vacas seropositivas, seropositivas con linfocitosis y seropositivas con linfosarcoma, respecto a vacas seronegativas. En cambio contrasta con Huber et ál. (1981), quienes no encontraron ninguna diferencia entre animales seronegativos y seropositivos.

Sin clasificar por número de lactancia o raza, las vacas seropositivas y seroconvertidas necesitan entre 0,12 a 0,38 más SPC que las seronegativas para quedar preñadas $(\mathrm{p}=0,031)$; asimismo, hubo una tendencia a que las seronegativas tuvieran menor cantidad de servicios por concepción. En el grupo de vacas con 1-2 lactancias hubo diferencia significativa entre seronegativos y seroconvertidas $(p=0,026)$, pero no con las seropositivos. La variable servicios 
Cuadro 4. Promedios de parámetros reproductivos según número de lactancias y estado serológico al VLBE en fincas lecheras especializadas de Costa Rica.

\begin{tabular}{|c|c|c|c|c|c|c|}
\hline Variable & Lactancia & Estado serológico & Total & Media & Error Estándar & $\mathrm{p}$ \\
\hline \multirow{9}{*}{$\begin{array}{l}\text { Intervalo } \\
\text { entre partos }\end{array}$} & \multirow[t]{3}{*}{$1-2$} & Seronegativo & 407 & $396,38^{\mathrm{a}}$ & 3,59 & \multirow[t]{3}{*}{0,0169} \\
\hline & & Seroconversión & 127 & $417,83^{b}$ & 7,89 & \\
\hline & & Seropositivo & 244 & $418,82^{\mathrm{b}}$ & 6,00 & \\
\hline & \multirow[t]{3}{*}{$3-5$} & Seronegativo & 615 & $388,46^{\mathrm{a}}$ & 5,85 & \multirow[t]{3}{*}{0,0376} \\
\hline & & Seroconversión & 120 & $402,87^{b}$ & 2,75 & \\
\hline & & Seropositiva & 536 & $408,99^{\mathrm{b}}$ & 3,61 & \\
\hline & \multirow[t]{3}{*}{$\geq 6$} & Seronegativa & 114 & $397,50^{\mathrm{a}}$ & 7,32 & \multirow[t]{3}{*}{0,4677} \\
\hline & & Seroconversión & 12 & $410,39^{\mathrm{a}}$ & 27,53 & \\
\hline & & Seropositiva & 152 & $409,75^{\mathrm{a}}$ & 6,27 & \\
\hline \multirow{9}{*}{$\begin{array}{l}\text { Servicios por } \\
\text { concepción }\end{array}$} & \multirow[t]{3}{*}{$1-2$} & Seronegativa & 372 & $2,05^{\mathrm{a}}$ & 0,08 & \multirow[t]{3}{*}{0,025} \\
\hline & & Seroconversión & 109 & $2,43^{\mathrm{b}}$ & 0,12 & \\
\hline & & Seropositiva & 227 & $2,17^{\mathrm{ab}}$ & 0,15 & \\
\hline & \multirow[t]{3}{*}{$3-5$} & Seronegativa & 525 & $1,79^{\mathrm{a}}$ & 0,11 & \multirow[t]{3}{*}{0,307} \\
\hline & & Seroconversión & 95 & $1,98^{\mathrm{a}}$ & 0,06 & \\
\hline & & Seropositiva & 475 & $2,12^{\mathrm{a}}$ & 0,07 & \\
\hline & \multirow[t]{3}{*}{$\geq 6$} & Seronegativa & 89 & $1,44^{\mathrm{a}}$ & 0,18 & \multirow[t]{3}{*}{0,158} \\
\hline & & Seroconversión & 9 & $2,19^{\mathrm{a}}$ & 0,44 & \\
\hline & & Seropositiva & 118 & $2,03^{\mathrm{a}}$ & 0,14 & \\
\hline \multirow[t]{9}{*}{ Días abiertos } & \multirow[t]{3}{*}{$1-2$} & Seronegativa & 372 & $127,36^{\mathrm{a}}$ & 2,67 & \multirow[t]{3}{*}{0,1178} \\
\hline & & Seroconversión & 109 & $147,82^{\mathrm{a}}$ & 6,72 & \\
\hline & & Seropositiva & 227 & $129,63^{\mathrm{a}}$ & 8,39 & \\
\hline & \multirow[t]{3}{*}{$3-5$} & Seronegativa & 525 & $127,68^{\mathrm{a}}$ & 2,56 & \multirow[t]{3}{*}{0,217} \\
\hline & & Seroconversión & 95 & $135,14^{\mathrm{a}}$ & 3,30 & \\
\hline & & Seropositiva & 475 & $115,55^{\mathrm{a}}$ & 5,79 & \\
\hline & \multirow[t]{3}{*}{$\geq 6$} & Seronegativa & 89 & $83,22^{\mathrm{a}}$ & 3,66 & \multirow[t]{3}{*}{0,0188} \\
\hline & & Seroconversión & 9 & $138,48^{b}$ & 47,24 & \\
\hline & & Seropositiva & 118 & $130,69^{b}$ & 6,92 & \\
\hline
\end{tabular}

Literales distintas indican diferencias significativas con nivel de significancia de 0,05.

por concepción arrojó diferencia significativa $(\mathrm{p}=0,026)$. En las categorías de 3-5 y $\geq 6$ lactancias, no hubo diferencias entre las 3 categorías; sin embargo, hubo una tendencia a mayores SPC en seroconvertidas y seropositivas (Cuadro 4).

En días abiertos, igualmente, hubo una tendencia a mayor cantidad en las vacas seroconvertidas y seropositivas, aunque estas no fueron estadísticamente significativas excepto en el grupo de animales con $\geq 6$ lactancias (Cuadro 4). Estos resultados, en general, coinciden con lo reportado por Pollari et ál. (1992) y Brenner et ál. (1989) que, aunque no reportan diferencias significativas entre vacas seronegativas y seropositivas, si registran una tendencia de las vacas seropositivas a tener más días abiertos que animales seronegativos. Es posible que en el grupo de las vacas $\geq 6$ lactancias se conserven una importante cantidad de animales seropositivas por ser superiores en rendimiento, por lo que se conservan en el hato a pesar de su estado. Desafortunadamente, no fue posible determinar, en este estudio, si eran parte de hatos segregados.

Finalmente, la raza no mostró tener asociación con el efecto del estado a VLBE sobre los parámetros analizados; de hecho, en todos los casos los datos fueron muy similares entre las 3 categorías de estado serológico cualquiera que fuese la raza (Cuadro 5). 
Cuadro 5. Promedios de parámetros reproductivos según raza y estado serológico al VLBE en fincas lecheras especializadas de Costa Rica.

\begin{tabular}{|c|c|c|c|c|c|c|}
\hline Variable & Raza & Estado serológico & Total & Media* & Error estándar & $\mathrm{p}$ \\
\hline \multirow{14}{*}{$\begin{array}{l}\text { Intervalo entre } \\
\text { partos }\end{array}$} & \multirow[t]{3}{*}{ Holstein } & Seronegativa & 406 & 410,51 & 3,58 & \multirow[t]{3}{*}{0,399} \\
\hline & & Seroconversión & 123 & 410,86 & 7,23 & \\
\hline & & Seropositiva & 568 & 423,30 & 3,81 & \\
\hline & \multirow[t]{3}{*}{ Jersey } & Seronegativas & 588 & 392,99 & 2,76 & \multirow[t]{3}{*}{0,46} \\
\hline & & Seroconvertidas & 78 & 399,19 & 9,48 & \\
\hline & & Seropositivas & 227 & 389,81 & 4,51 & \\
\hline & \multirow[t]{3}{*}{ Holstein x Jersey } & Seronegativas & 17 & 384,29 & 18,20 & \multirow[t]{3}{*}{0,677} \\
\hline & & Seroconvertidas & 16 & 376,44 & 13,37 & \\
\hline & & Serpositivas & 69 & 390,59 & 8,07 & \\
\hline & \multirow{2}{*}{ Guernsey } & Seronegativas & 64 & 446,80 & 10,73 & \multirow[t]{2}{*}{0,32} \\
\hline & & Seropositivas & 8 & 436,50 & 42,37 & \\
\hline & \multirow[t]{3}{*}{ Otras } & Seronegativas & 61 & 377,08 & 6,23 & \multirow[t]{3}{*}{0,40} \\
\hline & & Seroconvertidas & 42 & 398,78 & 12,12 & \\
\hline & & Seropositivas & 60 & 405,43 & 11,04 & \\
\hline \multirow{14}{*}{$\begin{array}{l}\text { Servicios por } \\
\text { concepción }\end{array}$} & \multirow[t]{3}{*}{ Holstein } & Seronegativas & 341 & 2,14 & 0,08 & \multirow[t]{3}{*}{0,115} \\
\hline & & Seroconvertidas & 93 & 1,98 & 0,15 & \\
\hline & & Seropositivas & 493 & 2,31 & 0,08 & \\
\hline & \multirow[t]{3}{*}{ Jersey } & Seronegativas & 520 & 1,85 & 0,06 & \multirow[t]{3}{*}{0,68} \\
\hline & & Seroconvertidas & 68 & 1,93 & 0,14 & \\
\hline & & Seropositivas & 208 & 1,95 & 0,11 & \\
\hline & \multirow{3}{*}{ Holstein $\mathrm{x}$ Jersey } & Seronegativas & 15 & 1,67 & 0,19 & \multirow[t]{3}{*}{0,96} \\
\hline & & Seroconvertidas & 14 & 2,00 & 0,50 & \\
\hline & & Serpositivas & 60 & 2,02 & 0,21 & \\
\hline & \multirow[t]{2}{*}{ Guernsey } & Seronegativas & 56 & 3,23 & 0,31 & \multirow[t]{2}{*}{0,608} \\
\hline & & Seropositivas & 7 & 2,71 & 0,71 & \\
\hline & \multirow[t]{3}{*}{ Otras } & Seronegativas & 54 & 1,80 & 0,15 & \multirow[t]{3}{*}{0,52} \\
\hline & & Seroconvertidas & 38 & 2,00 & 0,23 & \\
\hline & & Seropositivas & 52 & 2,19 & 0,21 & \\
\hline \multirow{14}{*}{ Días abiertos } & \multirow{3}{*}{ Holstein } & Seronegativas & 341 & 139,59 & 4,23 & 0,378 \\
\hline & & Seroconvertidas & 93 & 132,37 & 7,37 & \\
\hline & & Seropositivas & 493 & 152,17 & 4,31 & \\
\hline & Jersey & Seronegativas & 520 & 117,79 & 2,93 & 0,196 \\
\hline & & Seroconvertidas & 68 & 116,59 & 7,75 & \\
\hline & & Seropositivas & 208 & 116,51 & 5,40 & \\
\hline & H4J4 & Seronegativas & 15 & 118,40 & 12,20 & 0,561 \\
\hline & & Seroconvertidas & 14 & 122,93 & 18,83 & \\
\hline & & Serpositivas & 60 & 110,88 & 7,95 & \\
\hline & Guernsey & Seronegativas & 56 & 185,68 & 13,65 & 0,526 \\
\hline & & Seropositivas & 7 & 162,43 & 37,07 & \\
\hline & Otras & Seronegativas & 54 & 105,76 & 6,99 & 0,221 \\
\hline & & Seroconvertidas & 38 & 102,55 & 10,63 & \\
\hline & & Seropositivas & 52 & 117,79 & 8,80 & \\
\hline
\end{tabular}

* En ninguno de los casos hubo diferencias entre las medias.

\section{CONCLUSIONES Y RECOMENDACIONES}

Si bien es cierto los resultados de este estudio no proporcionan datos contundentes sobre la relación del estado serológico al VLBE con 3 de los principales parámetros reproductivos que se analizan en las lecherías especializadas, sí se pudo comprobar alguna relación importante con el intervalo entre partos y los servicios por 
concepción, no así con los días abiertos; además, aunque no hubo significancia estadísticas en muchas de las diferencias encontradas, los animales seronegativos mostraron mejores indicadores que los seroconvertidos y los seropositivos. Adicionalmente, un estudio complementario a este (Romero et ál. 2012) documenta una reducción significativa en la producción de leche en vacas seroconvertidas y seropositivas, lo que ofrece elementos a tomar en cuenta para la decisión sobre el programa que se desee implementar en cada finca particular para controlar el VLBE.

La sola utilización de una encuesta, o la realización de una serie de preguntas sobre factores de manejo de la finca relacionados con la transmisión del VLBE, no es suficiente para establecer un diagnóstico presuntivo de la situación del virus en un hato; esto porque el productor tiene conocimiento sobre el tema y responderá lo que la teoría dice y no necesariamente lo que realiza. De ese modo, la inspección meticulosa del hato, las entrevistas a profundidad y el muestreo serológico se vuelven las herramientas indispensables para un diagnóstico más aproximado a la realidad.

Cuando de cualquier enfermedad infectocontagiosa se trata, que no sea de impacto directo en la salud pública cuyo combate es obligatorio, siempre la recomendación será proceder con los siguientes pasos: 1) diagnosticar su presencia, 2) determinar la prevalencia y, de ser posible, la incidencia, 3) establecer el real efecto de la enfermedad por comparación de parámetros de interés que hayan sido registrados correctamente, 3 ) realizar un estudio de beneficio-costo de la implementación de un plan según los pasos anteriores. Realizar cualquier programa que implique costos significativos, sin haber pasado por este análisis, podría significar más costos que beneficios.

\section{LITERATURA CITADA}

ALVARADO K., ROMERO J.J., VALVERDE E. 2007. Caracterización de la detección de celos en fincas lecheras especializadas de Costa Rica. Ciencias Veterinarias (Costa Rica) 24:167-184.
ARGIMON J., JIMÉNEZ J. 1991. Métodos de investigación clínica y epidemiológica. Sa. Harcourt. Madrid, Esp. $393 \mathrm{p}$.

BEITA G. 2008. Epidemiología de la leucosis enzoótica bovina en hatos lecheros especializados. Tesis de licenciatura, Universidad Nacional, Heredia, C.R. 53 p.

BRENNER J., VAN HAAM M., SAVIR D., TRAININ Z. 1989. The implication of BLV infection in the productivity, productive capacity and survival rate of dairy cow. Vet. Immunol. Immunopathol. 3:299-305.

DANIEL W. 2002. Bioestadística: Base para el análisis de la ciencias de la salud. $4^{\text {a }}$ Ed. Limusa Wiley. 892 p.

DETILLEUX J., FREEMAN A., MILLER L. 1991. Comparison of natural transmission of bovine leukemia virus in Holstein cows of two genetic lines selected for high and average milk production. Am. J. Vet. Res. 52:1551-1555.

DI RIENZO J.A., CASANOVES F., BALZARINI M.G., GONZALEZ L., TABLADA M., ROBLEDO C.W. 2008. InfoStat, versión 2008, Grupo InfoStat, FCA, Universidad Nacional de Córdoba, Argentina. 336 p.

DOLZ G., MORENO E. 1999. Comparasion of agar gel inmunodiffusion test, enzyme-linked inmunoabsorbent assay and Wester Boltting for deteccion of BLV antibodies. J. Vet. Med. 46:551558.

D’ANGELINO J.L., GARCIA M., GIRGEL E.H. 1998. Productive and reproductive performance in cattle infected with bovine-leukosis virus. J. Dairy Res. 65:693-695.

GONZÁLEZ E. 1977. Linfoma: Descubren enfermedad mortal en el ganado. Agroindustria 6:15-18.

GREENBERG R.S., FLANDERS W.D., ELEY J.W., DANIELS S.R., BORING J.R. 2001. Epidemiología médica. Manual Moderno. $3^{\text {a }}$ Ed. 239 p.

HOPKINS S.G., DIGIACOMO R.F. 1997. Natural transmission of bovine leukemia virus in dairy and beef cattle. Vet Clin North Am Food Anim Pract. 13:107-128.

HUBER N.L., DIGIACOMO R.F., EVERMANN J.F., STUDER E. 1981. Bovine leukemia virus infection in a large Holstein herd: prospective comparison of production and reproductive performance in antibody-negative and antibody-positive cows. Am. J. Vet. Res. 42:1477-1481.

JIMÉNEZ C., BONILLA J., DOLZ G., RODRÍGUEZ L., HERRERO L., BOLAÑOS E., CORTEZ M., MORENO E. 1995. Bovine Leukemia virus Infection in Costa Rica. J. Vet. Med. 42:385-390.

JOHNSON R., KANEENE J.B. 1991. Bovine leukemia virus. Part IV. Economic impact. Comp. Cont. Educ. Proc. Vet. 11:1727-1737.

KETTMANN R., CLEUTER Y., MAMMERICKX M., MEUNIR M., BERNARDI G., BURNY A., CHANTRENNE H. 1980. Genomic integration of 
bovine leukemia provirus: comparison of persistent lymphocytosis with the lymph node tumor form of enzootic bovine leucosis. Proc. Natl. Acad. Sci. 77:257-258.

MORA D. 1997. Evaluación de prácticas de manejo asociadas al riesgo de transmisión del virus de la leucosis enzoótica bovina en hatos lecheros de Costa Rica. Tesis de licenciatura, Universidad Nacional, Heredia, C.R. 103 p.

MURPHY F., GIBBS J., HORZINEK M., STUDDERT M. 1999. Veterinary Virology. $3^{\text {th }}$ ed. 629 p.

NEKOUEI O., VANLEEUWEN J., SANCHEZ J., KELTON D., TIWARI A., KEEFE G. 2015 Herd-level risk factors for infection with bovine leukemia virus in Canadian dairy herds. Prev Vet Med. 119:105-113.

NOORDHUIZEN J.P.T.M., BUURMAN J. 1984. Veterinary automated management and production control program for dairy farms (VAMPP). The application of MUMPS for data processing. Vet Q. 6:62-77.

POLLARIF.L., WANGSUPHACHART V.L., DIGIACOMO R.F., EVERMANN J.F. 1992. Effects of bovine leukemia virus infection on production and reproduction in dairy cattle. Can. J. Vet. Res. 4:289-295.
RADOSTITS O., GAY C., BLOOD D., HINCHCLIFF K. 2001. Medicina veterinaria. Tratado de las enfermedades del ganado, ovino, porcino y equino. Editorial Interamericana, España. 1206 p.

RODRÍGUEZ L., ESQUIVEL R., ALVARADO J. 1980. Estudio de leucosis bovina en hatos lecheros del valle central de Costa Rica. Ciencias Veterinarias (Costa Rica) 2:183-194.

ROMERO J.J., DÁVILA G., BEITA G., DOLZ G. 2012. Efecto del estatus serológico al virus de la leucosis enzoótica bovina (BLV) sobre la producción de leche en hatos lecheros de Costa Rica. Ciencias Veterinarias (Costa Rica) 30: 39-51.

ROMERO J.J., ROJAS J., ESTRADA S. 2011. El programa VAMPP Bovino como herramienta de apoyo a la toma de decisiones en los sistemas de producción bovinos. Ventana lechera 5:4-14.

SVANOVA 2015. Bovine leukemia virus gp51 antibody test BLV- gp51. Consultado 7 Julio 2015. Disponible en http://www.svanova.com/content/dam/internet/ah/ svanova/dk_EN/documents/Kit\%20inserts/Insert\%20 BLV\%20gp51-Ab\%2019-2351-00-94_05.pdf 